\title{
The effect of body postures on the distribution of air gap thickness and contact area
}

\author{
Emel Mert $^{1,2} \cdot$ Agnes Psikuta $^{1} \cdot$ Marie-Ange Bueno ${ }^{2} \cdot$ René M Rossi $^{1}$
}

Received: 1 April 2016 / Revised: 22 June 2016 / Accepted: 15 July 2016 / Published online: 13 August 2016

(C) ISB 2016

\begin{abstract}
The heat and mass transfer in clothing is predominantly dependent on the thickness of air layer and the magnitude of contact area between the body and the garment. The air gap thickness and magnitude of the contact area can be affected by the posture of the human body. Therefore, in this study, the distribution of the air gap and the contact area were investigated for different body postures of a flexible manikin. In addition, the effect of the garment fit (regular and loose) and style (t-shirts, sweatpants, jacket and trousers) were analysed for the interaction between the body postures and the garment properties. A flexible manikin was scanned using a threedimensional (3D) body scanning technique, and the scans were post-processed in dedicated software. The body posture had a strong effect on the air gap thickness and the contact area for regions where the garment had a certain distance from the body. Furthermore, a mathematical model was proposed to estimate the possible heat transfer coefficient for the observed air layers and their change with posture. The outcome of this study can be used to improve the design of the protective and functional garments and predict their effect on the human body.
\end{abstract}

Keywords Air gap thickness $\cdot$ Contact area $\cdot$ Heat transfer in clothing $\cdot$ Body posture

Agnes Psikuta

agnes.psikuta@empa.ch

1 Empa, Swiss Federal Laboratories for Materials Science and Technology, St. Gallen, Switzerland

2 University Haute Alsace, Laboratoire de Physique et Mécanique Textiles, Ecole Nationale Supérieure d'Ingénieurs Sud Alsace, Mulhouse, France

\section{Introduction}

Clothing has a basic function to protect the human body from external hazards or unpleasant environments and to keep it in a convenient microenvironment. An individual should have a state of well-being in the protective clothing to be able to sustain work and properly respond to the situations in the harsh environmental conditions. In the last decades, the systematic and extensive evaluations of the thermal comfort, protective performance and ergonomics of the clothing have been widely addressed, especially for the protective garments (ASTM D 1518:2010; ISO 7730:2005; ASTM F 2370:2010; ISO 9920:2007). However, most of the testing methods and studies predominantly focused on the standing straight posture which is an unlikely situation for the working conditions and requirements at a workplace. Therefore, to maintain the protection of the body in various conditions, including postures required for a given work, the protection parameters and thermal comfort of human body should be investigated in terms of the protective garment design.

The heat and moisture transfer through the garment is not only dependent on the properties of the fabric used in the garment, but to a great extent on the magnitude of and change in the contact area and the thickness of the air layers underneath and between garment layers, and outer adjacent air layer (Spencer-Smith 1977; Mert et al. 2015). In these air layers, a number of physical processes, such as dry heat transfer (conduction, convection and radiation), evaporation and wicking of liquid sweat from the skin (in areas of contact), occur and influence the well-being of the human body (Parsons 2003). Specifically, the fabric which is in direct contact with the skin can take up the sweat from the skin and spread it to a larger area on the fabric, where the heat loss may increase due to evaporation (Takada et al. 1999; Umeno et al. 2001). The thickness of air layers and the magnitude of contact area 
can be affected by the mechanical properties of the fabric and the garment properties (Mah and Song 2010; FrackiewiczKaczmarek et al. 2014b), moisture content (for example, due to rain or excessive sweating) (Frackiewicz-Kaczmarek et al. 2014a), posture and the movement (Kirk and Ibrahim 1966; Li et al. 2011), which can lead to heterogeneous heat transfer in clothing.

The two-dimensional pattern of the garment for the 3D body is made based on the measurements of the human body in the standing straight posture. Thus, the confectioned garment fits best to the body shape in this posture, and depending on the garment style (ease between the garment and the body), either it conforms snugly to the body geometry or sags according to the mechanical properties of the fabric (drapability, bending rigidity). Ideally, the garment should maintain the wearing comfort and fulfil the space demand of the bent joint in various postures as it is in the standing straight posture and still help to achieve the desired level of comfort and the needed protection against external hazards. Nevertheless, the body dimensions change with a posture change (Aldrich 1998; Lee and Ashdown 2005; Choi and Ashdown 2011) and the garment needs to drape to allow room for the body in the changed posture. In some cases, the clothing can restrict the mobility of the body (Dorman and Havenith 2009) or even further change the body shape by a compression (Pheasant 2003). Kirk and Ibrahim evaluated the critical strain areas (knee, hip, back and elbows) at the body due to the effect of dynamic change in the body posture (Kirk and Ibrahim 1966) and found that the garment at the strained convex area of the bent joint could be stretched or relocated, whilst it is buckled on the concave side. Thus, the thickness and the shape of the air layer and the magnitude of the contact area will obviously change at and around the bent joints. This phenomenon has not been yet quantified in terms of air gap thickness change and its effect on the heat loss of the human body.

The importance of the air layer thickness for the heat and mass transfer through ensemble is well recognized and has been studied to a great extent in benchtop tests (SpencerSmith 1977 ; Oh 2008; Hes and de Araujo 2010). However, these methods are limited to the evaluation of either even thickness of air layers or its full contact and hardly applicable for evaluation of a whole garment performance. The overall or local effect of the air layers in the clothing has been studied using thermal manikins (McCullough et al. 1985; Oliveira et al. 2008) or human subjects (Nielsen et al. 1985) in the standardized laboratory tests in standing straight posture (ASTM D 1518:2010; ISO 9920:2007, ISO 15831:2004). Some researchers used agile thermal manikins (Olesen et al. 1982 ; Wu et al. 2011) or human subjects in various postures (Havenith et al. 1990a, b) to evaluate the effect of posture on the insulation of the clothing allowing a realistic formation of the air layers and contact areas in standing and sitting postures. Despite the informative nature of these studies, their major drawbacks include limited segmentation for the local thermal effects and the bending range of the limbs in manikins, and high intra-subject variability, relaying on only a discrete number of spot measurements, low posture and body shape control in human subject studies. In both manikin and human subject methods, it is rather difficult or not possible to differentiate between the contributing heat transfer mechanisms (conduction, convection and radiation) and the factors related to the garment design and fabric properties. On the other hand, the clothing mathematical models could complement these methods by providing more detailed information on heat transfer mechanisms for given fabrics and air layers. Nonetheless, till now, they assumed an even air layer thickness between the body and the garment or its full contact (Lotens and Havenith 1991; Li and Holcombe 1998; Fan et al. 2000), which simplifies the computation process of the simulation, but disregards the spatial geometry of the air layers and its impact on the heat loss (Mayor et al. 2014, 2015; Mert et al. 2015). Consequently, these assumptions could result in overestimation or underestimation of the heat transfer through the garment unless the adequate air layer thickness and contact area will be used in such clothing models.

The protective performance of the clothing against the heat transfer is higher when the body is in stationary condition due to the higher insulation of the stagnant air underneath the garment. This protective performance of the garment decreases when forced convection due to the movement of the body parts or compression by wind occurs (Winslow et al. 1939; Havenith and Nilsson 2004). During keeping a stationary posture, such as driving, office work, assembly work, the excessive convective heat loss due to the movement of the limbs or wind is usually not present, hence, the insulation of the body is predominantly provided by the presence of the stagnant air beneath the garment.

In this study, the distribution of the air gap thickness and the contact area were investigated for different stationary body postures. In addition, the effect of the garment fit (regular and loose) and style (t-shirts, sweatpants, jacket and trousers) were analysed to see the interaction between the body postures and the garment properties. The study was performed using a flexible manikin which was scanned using a 3D body scanning technique and the scans were post-processed in the dedicated software.

\section{Methods}

\section{The manikin}

To mimic the stationary postures of the human body, which are mostly found during work or leisure time, a flexible manikin with the approximate size of an adult male body has been selected. It is made of polyurethane foam with plastic coating 
(Polyform ${ }^{\circledR}$ GmbH \& Co. KG., Germany) with the circumference of $91 \mathrm{~cm}$ at the chest, $77 \mathrm{~cm}$ at the waist and $91 \mathrm{~cm}$ at the hips. The manikin's posture can be changed by bending the joints at the neck, shoulders, elbows, wrists, waist, hips, knees, ankles and fingers.

\section{Postures}

In the present study, the angles of the limb joints for upper and lower body have been chosen for stationary and ergonomically correct body postures. For stationary body postures, the joint angles should be within the range as in relevant standards (ISO 11226:2000) to avoid the overload on the ligaments, the cartilage and the intervertebral disks. Table 1 shows the selection of the postures with various joint angles of the human body and their relevance with real-life situations (Pheasant 2003; ISO 11226:2000; Grandjean 1980; Wang and Bullock 2004). In addition, to be able to make comparison with previous studies (Mah and Song 2010; Psikuta et al. 2012), standing posture was selected as a reference.

\section{Fabrics and garments}

The selection of the fabrics to make garments was done based on the typical textiles which are used in casual garments. Plain knitted jersey (including $95 \%$ cotton and $5 \%$ Spandex with $186 \mathrm{~g} / \mathrm{m}^{2}$ of weight (ISO 9073:-1:1989), $0.83 \mathrm{~mm}$ of thickness (ISO 5084:1996) and $38 \%$ of drape coefficient (ISO 90739:2008)) and 3/1 twill woven fabric (including $100 \%$ cotton with $345 \mathrm{~g} / \mathrm{m}^{2}$ of weight (ISO 9073-1:1989), $1.13 \mathrm{~mm}$ of thickness (ISO 5084:1996) and $67 \%$ of drape coefficient) were used to make the casual garments. The fabrics were washed with gentle washing programme at $40{ }^{\circ} \mathrm{C}$ and dried to remove any foreign material and the tensions of the manufacturing process. The fabrics were ironed before confectioning.

Casual sweatpants and t-shirts made of plain knitted jersey fabric were prepared for this study to represent the underwear or indoor casual clothing, whilst trousers and jacket made of 3/1 twill woven fabric represented the protective or outdoor casual clothing. Sweatpants and t-shirts were done in regular and loose fit and the trousers and the jacket were confectioned in loose fit. Ease allowances of the garments calculated by subtracting the girth of the manikin body from the girth of the garment at the relevant body landmarks are given in Table 2 . The garments were conditioned in the standard atmospheric conditions $\left(20{ }^{\circ} \mathrm{C}, 65 \%\right)$ for at least $24 \mathrm{~h}$ before measurements.

Close-ended zippers were added to designs to dress and undress the manikin easily and avoid the disturbance on the manikin's posture. Since a zipper in the garment influences the draping of the garment due to its stiff structure, the zippers were added at the left back side of the t-shirts and jacket and along the left side seam of the sweatpants/trousers (Fig. 1) and only the right part of the body evaluated. Additionally, during scanning process, the back of the trunk and the back of the lower body (except for the calf) could not be scanned in the sitting posture due to the chair. Therefore, for sitting postures, the results of the back of the trunk and buttocks were not evaluated. However, the posterior thigh could be evaluated by scanning the garment till the fabric touches the chair. In the post-processing software, a feature for the chair was created, and in this way, the air gap thickness and the contact area for posterior thigh were evaluated.

\section{D scanning and post-processing}

A hand-held 3D body scanner Artec MHT (Artec Group, USA) was used to capture the clothed and the nude manikin shapes in the relevant postures. Since the hand-held scanner has a small view area $(536 \times 371 \mathrm{~mm})$, the scanner had to be moved around the manikin to be able to scan the large size of the manikin. For scanning in the standing postures, a special driver was used according to the advanced method developed in earlier studies (Psikuta et al. 2012; Frackiewicz-Kaczmarek et al. 2012; Psikuta et al. 2015), whilst for scanning in the sitting posture, the scanner was used with guidance of a person. A wooden reference, a chair with adjustable back, white cylindrical structures, and wooden plates were used for better scanning performance and reliability of scans. The repeatability of scans for upper and lower body using both a hand-held and a driver scanning methods has been found to be $0.9 \mathrm{~mm}$ according to the method developed in a previous study (Psikuta et al. 2015). The 3D scans were post-processed using the dedicated software Geomagic Control 2014 (3D Systems®, USA) to compute the thickness of air gap and the magnitude of contact area.

\section{Measurement protocol}

Scanning and post-processing procedure included the following steps (Psikuta et al. 2012; Frackiewicz-Kaczmarek et al. 2012; Psikuta et al. 2015):

- Dressing the flexible manikin and mimicking the posture on the relevant stand

- Scanning dressed flexible manikin locally in a given posture

- Undressing the flexible manikin with the help of zippers and without changing its posture

- Scanning the nude flexible manikin locally in a given posture on the relevant stand

- Post-processing of scans including cleaning artefacts and alignment of dressed and nude manikin scans using uncovered body parts and reference objects as a reference

- Geometrical determination of the distance between superimposed surfaces recognized as the air gap thickness and contact area 
Table 1 Selected body postures

\begin{tabular}{|c|c|c|c|c|c|}
\hline $\begin{array}{l}\text { Body } \\
\text { region }\end{array}$ & Posture & Acting joint & Angle & $\begin{array}{l}\text { Related real-life } \\
\text { situation }\end{array}$ & Posture scheme \\
\hline \multirow{5}{*}{$\begin{array}{l}\text { Upper } \\
\text { body }\end{array}$} & $\begin{array}{l}\text { Standing } \\
\text { (U1) }\end{array}$ & $\begin{array}{l}\text { Shoulder flexion / Elbow } \\
\text { flexion }\end{array}$ & $0^{\circ}$ & $\begin{array}{l}\text { Upright standing } \\
\text { position, reference }\end{array}$ & \\
\hline & $\begin{array}{l}\text { Standing } \\
\text { (U2) }\end{array}$ & Elbow & $90^{\circ}$ & $\begin{array}{l}\text { Office work at the } \\
\text { high desk }\end{array}$ & \\
\hline & $\begin{array}{l}\text { Standing } \\
\text { (U3) }\end{array}$ & $\begin{array}{l}\text { Shoulder flexion / Elbow } \\
\text { flexion }\end{array}$ & $30^{\circ} / 120^{\circ}$ & $\begin{array}{l}\text { Assembly } \\
\text { workers at the } \\
\text { high desk }\end{array}$ & \\
\hline & $\begin{array}{l}\text { Sitting } \\
\text { (U4) }\end{array}$ & Elbow / hip & $120^{\circ} / 90^{\circ}$ & $\begin{array}{l}\text { Assembly } \\
\text { workers at the } \\
\text { lower desk }\end{array}$ & \\
\hline & $\begin{array}{l}\text { Sitting } \\
\text { (U5) }\end{array}$ & Elbow / hip & $120^{\circ} / 110^{\circ}$ & $\begin{array}{l}\text { Driving, leisure } \\
\text { time }\end{array}$ & \\
\hline \multirow{4}{*}{$\begin{array}{l}\text { Lower } \\
\text { body }\end{array}$} & $\begin{array}{l}\text { Standing } \\
\text { (L1) }\end{array}$ & Trunk / Hip / Knee & $0^{\circ}$ & $\begin{array}{l}\text { Upright standing } \\
\text { position, reference }\end{array}$ & \\
\hline & $\begin{array}{l}\text { Standing } \\
\text { (L2) }\end{array}$ & $\begin{array}{l}\text { Knee (standing with one } \\
\text { leg on a footstep) }\end{array}$ & & $\begin{array}{l}\text { Assembly/office } \\
\text { workers at high } \\
\text { desk }\end{array}$ & \\
\hline & Sitting (L3) & Trunk / Hip / Knee & $\begin{array}{l}0^{\circ} / 90^{\circ} / \\
90^{\circ}\end{array}$ & Sedentary work & \\
\hline & Sitting (L4) & Trunk / Hip / Knee & $\begin{array}{l}0^{\circ} / 110^{\circ} / \\
120^{\circ}\end{array}$ & $\begin{array}{l}\text { Driving, relaxed } \\
\text { sedentary activity }\end{array}$ & \\
\hline
\end{tabular}


Table 2 Ease allowances in the garments used in the study (measured according to ISO 8559:1989)

\begin{tabular}{llllll}
\hline Upper body & \multirow{2}{*}{ Garment type } & \multicolumn{4}{l}{ Ease allowance at girth $(\mathrm{cm})$} \\
& & Chest & Waist & Hips & Biceps \\
& Regular t-shirt & 1 & 6 & 1 & 3.5 \\
& Loose t-shirt & 7 & 15 & 3 & 7.5 \\
& Jacket & 15 & 23 & 15 & 10.5 \\
Lower body & Garment type & \multicolumn{2}{l}{ Ease allowance at girth $(\mathrm{cm})$} \\
& & Hip & Thigh & Calf \\
& Regular sweatpants & 13 & 2.5 & 1.5 \\
& Loose sweatpants & 17 & 8.5 & 9.5 \\
& Trousers & 21 & 10.5 & 10.5 \\
\hline
\end{tabular}

The determination of the air gap thickness and the contact area were performed for individual body regions (Fig. 1). The air gap thickness was calculated as the average distance between the scanned clothed and the scanned nude manikin body, whilst the contact area was acquired as the percentage of the area where the scanned nude and scanned clothed manikin is in direct contact (Psikuta et al. 2015).

\section{Statistical analysis}

In order to evaluate the homogeneity in groups of data, such as the average air gap thickness and the contact area in various postures for different fit and style of garment, two-way analysis of variance (ANOVA) with Levene's test were performed using statistical software PASW® Statistic Version 22.0 (IBM, SPSS Inc, USA). However, the assumption of the homogeneity of variance was violated for most cases. And hence, logarithmic transformation was applied to the air gap thickness and the contact area results, which also ended up with violated assumption of the homogeneity of variance. And therefore, the outcome of the statistical analysis is not reported in the paper and the trends in the data have been evaluated with regard to the effect of posture on the air gap thickness and the contact area with different garment fit and style.

\section{Results}

Figure 1 presents the division of the body, the exemplary pictures and colour maps of post-processed 3D scans of $t$ shirts and a jacket for upper body, and sweatpants and trousers for lower body in relevant postures. These colour maps show the differences in air gap (red and yellow areas) and contact areas (blue and green areas) through used body postures.

Figures 2 and 3 show the mean air gap thickness and the mean contact area of four repetitions and their standard deviations for body regions adjacent to bent joints, such as the elbow, shoulder, hip for upper body and hip and knee for lower body, respectively. In some cases, the further body regions to the bent joint were included in the analysis whenever such interaction was observed. The air gap thickness and the contact area were reported for individual body regions according to the body divisions in Fig. 1.

In Fig. 3, the mean air gap thickness and the mean contact area were plotted against the lower body postures. The asymmetric posture results (L2 in Table 1) were plotted to the left of the reference standing posture and the symmetric sitting posture results to the right to allow direct comparison of these distinct postures and show results according to the increasing limb angles (L1, L3 and L4 in Table 1).

\section{Discussion}

\section{Global trend}

The results of the presented study showed that the effect of posture change on the distribution of the air gap thickness and the contact area are highly dependent on the body regions (Figs. 2 and 3). The selected postures for the upper body had an effect on the air gap thickness only at the abdomen, lumbus and pelvis area, where the garment hanged downwards with a certain distance from the body below the protruding body points (shoulder blades and breasts). The air gap thickness at the upper trunk was unaffected regardless of the bending the elbow or hips, or flexing the shoulder (Fig. 2c, e). For the lower body, the effect of posture change on the air gap thickness and the contact area was stronger on the legs than at the pelvis area (Fig. 3a-f). In the case of the contact area for both the upper and lower body, the selected postures had an effect at all body regions (Fig. 2b, d, f, h, j and 3b, d, f). As a result of flat and inclined shape of the upper trunk and posterior pelvis (hip), the garment fell on the body and conformed to it due to the limpness and weight of the fabric. This finding for the upper body is consistent with the findings from previous studies (Psikuta et al. 2012; Frackiewicz-Kaczmarek et al. 2014a, b), which investigated the effect of the garment style (shirt or t-shirt) and garment fit (tight, regular and loose) on the air gap thickness and the contact area at the upper body. Consequently, the results of the presented study showed that the change in the air gap thickness at the lower trunk and lower body due to the selected posture is a challenge for modelling of air layers and should be considered separately for the individual body regions, whilst it can be assumed uniform and constant for the upper trunk.

\section{Effect of body posture for the upper body}

Bending (which compresses the garment) and flexing (which elongates the garment) the joints had contrary effects on the distortion of the garment. By bending the joints, the length of 

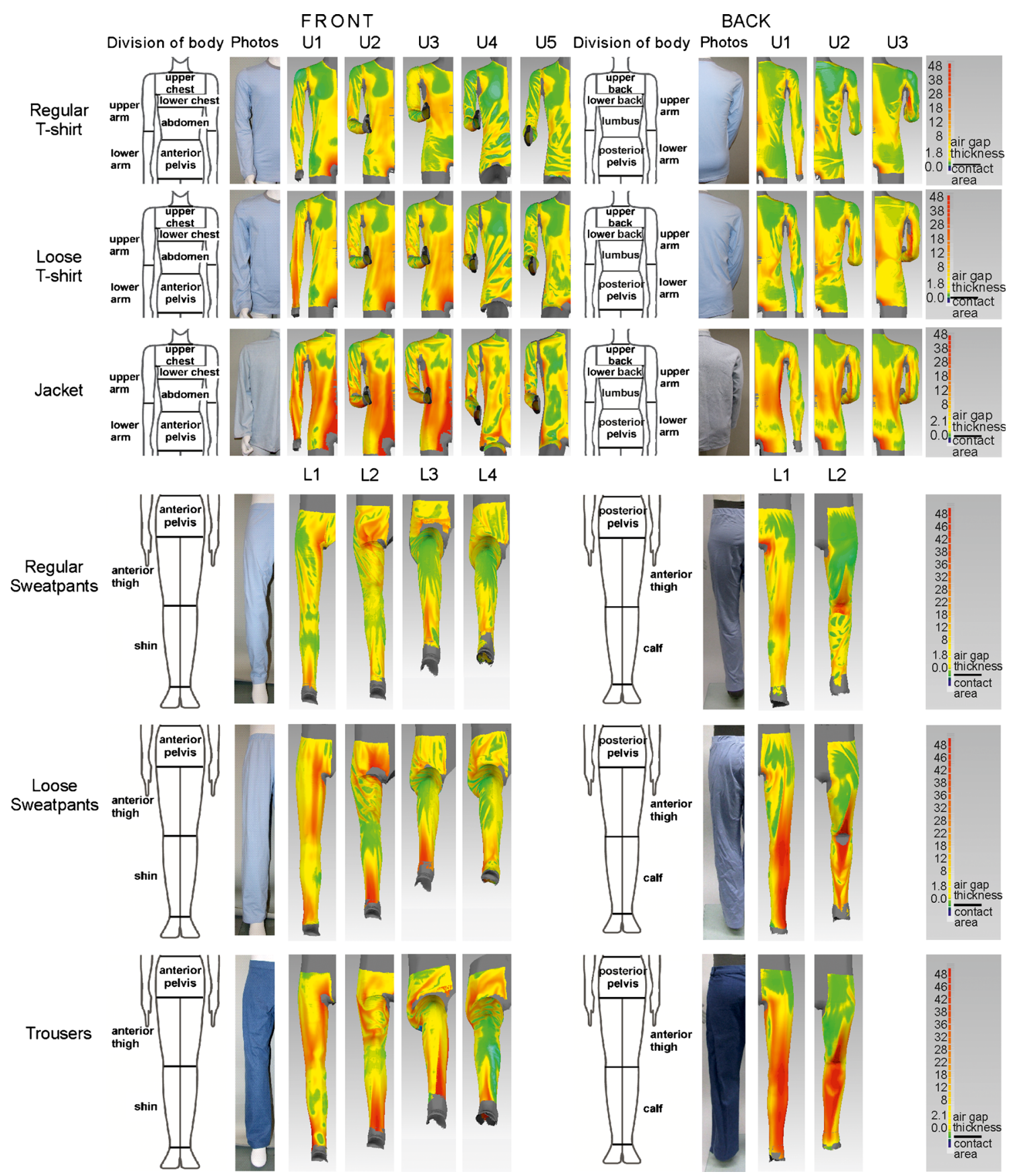

Fig. 1 The division of the manikin's upper and lower body into individual body parts (from front and back) to calculate the air gap thickness and the contact area and exemplary pictures and colour maps

the convex side of the bent joint increased, and the length of the concave side decreased. As a result of this change, the elongation and the compression/buckling were imposed on the garment in addition to the change in direction of the gravitational force due to change in the orientation of the body part (Kirk and Ibrahim 1966). For example, the air gap thickness decreased and the contact area increased on both sides of the joint at the upper arm (Fig. 2a, b, between U1 and U2), abdomen (Fig. 2g, h, between U3 and U4). For the anterior pelvis of upper and lower body with regular and loose t-shirts and sweatpants, jacket and trousers in various postures from front and back view

for upper body garments, the air gap thickness decreased, but the contact area increased only for the jacket (Fig. 2i, j, between U3 and U4). On the other hand, the flexion and the

Fig. 2 Mean air gap thickness and contact area and their standard deviations plotted for the relevant postures (U1, U2, U3 and U5 for arm and U1, U3, U4 and U5 for trunk) in two t-shirts and a jacket presented for individual body regions which are directly adjacent body regions to the elbow $(\mathbf{a}, \mathbf{b})$ and to the shoulder and hip $(\mathbf{c}-\mathbf{j})$. 

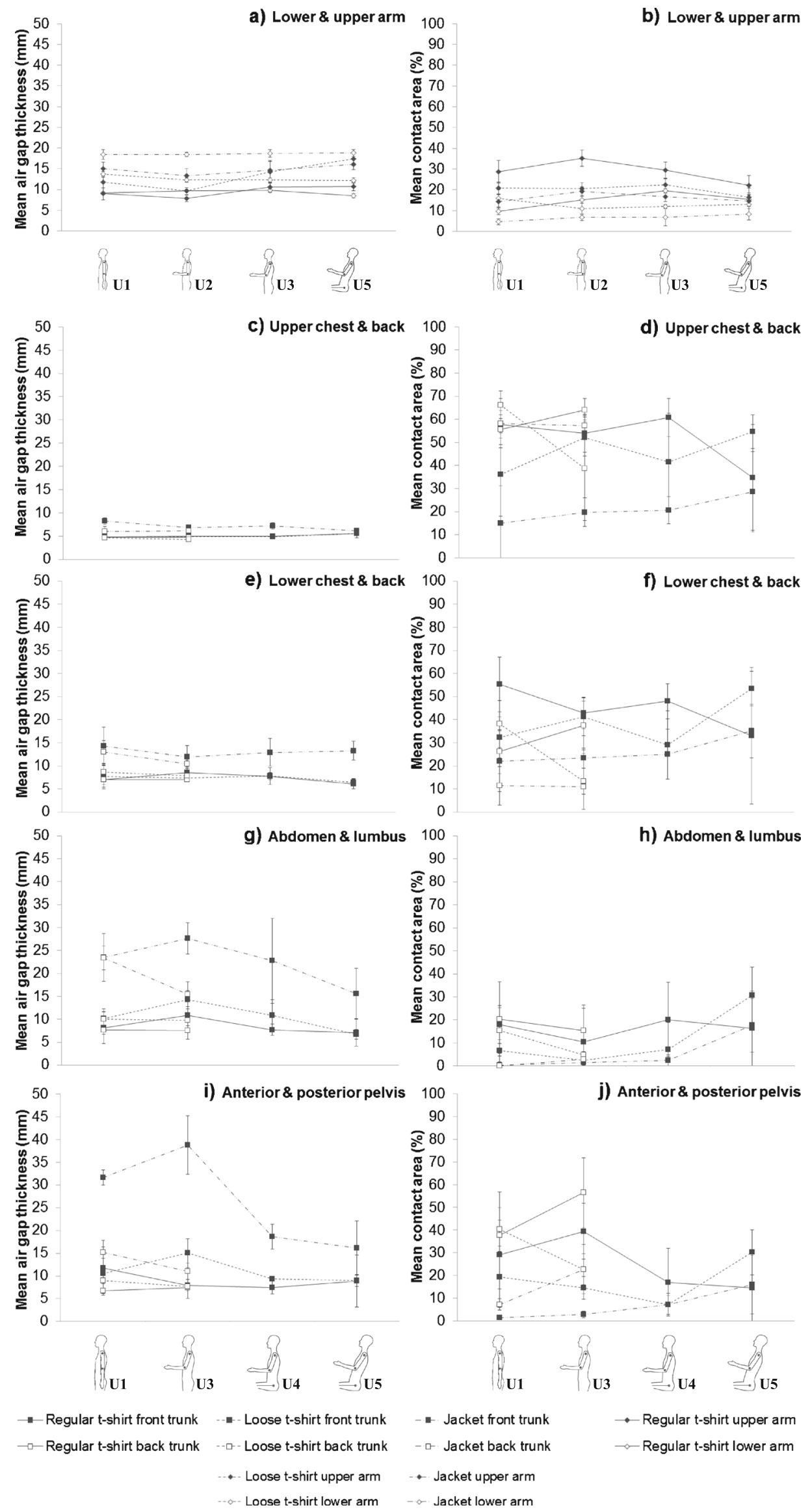

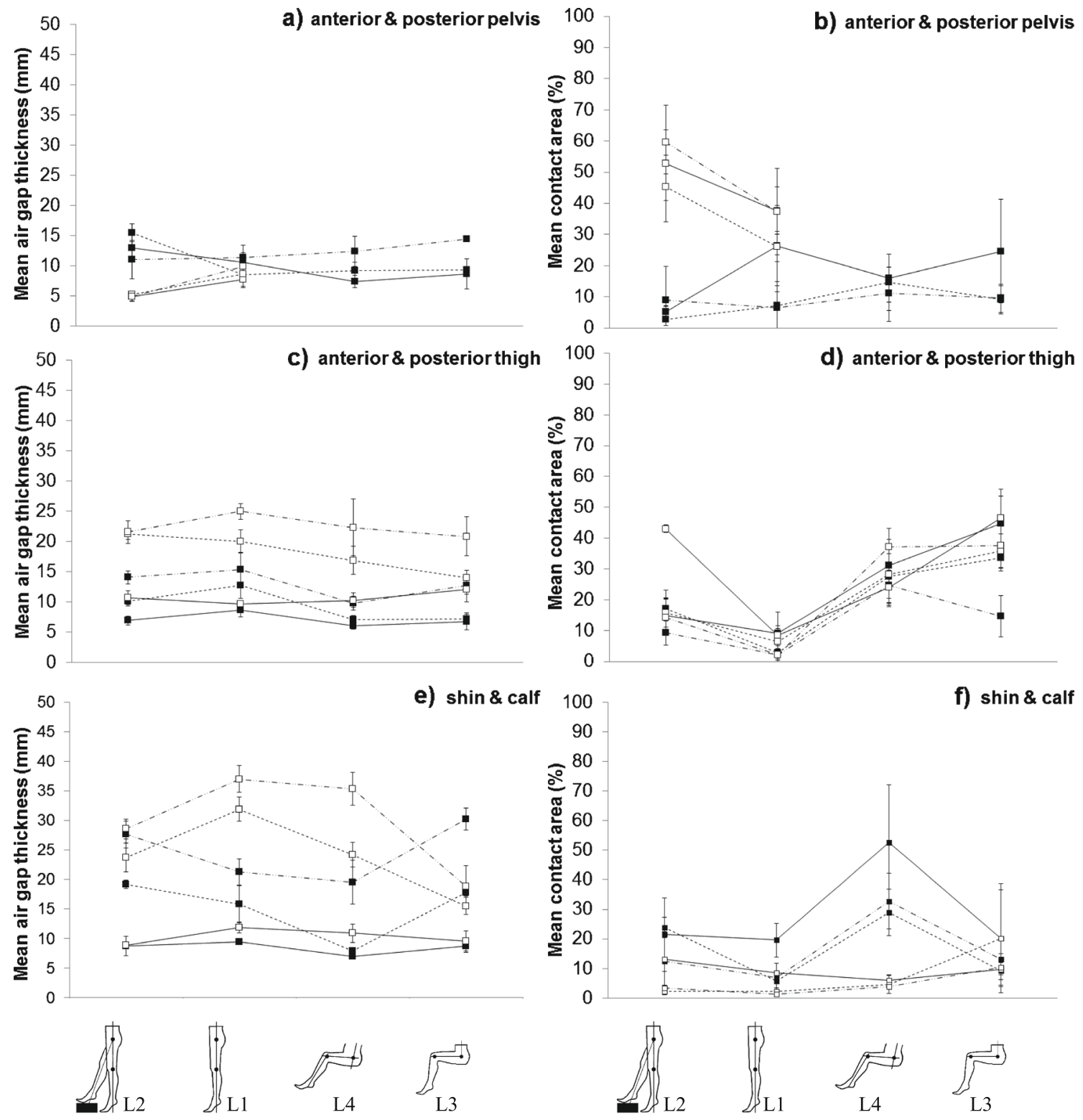
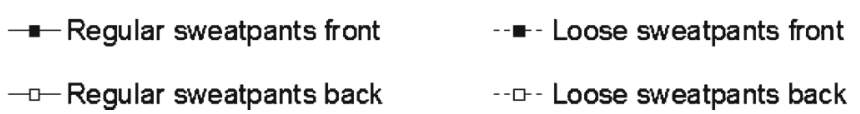

at the lower body (a, b for anterior and posterior pelvis, $\mathbf{c}, \mathbf{d}$ for anterior and posterior thigh, $\mathbf{e}, \mathbf{f}$ for shin and calf)

deviations plotted for the relevant postures (L1, L2, L3 and L4) in two sweatpants and a trousers presented for individual body regions which are

abduction of the arms using shoulder joint had an opposite effect on both parameters than bending the joints. During joint flexing, the garment in contact with the concave part of the joint is compressed/buckled and the garment in contact with the convex part of the joint is elongated. And, as a result, the air gap thickness increased and the contact area decreased at the abdomen (Fig. 2g, h, between U1 and U3), whereas the opposite trends were observed for the lumbus. When the ease allowance is sufficient as in the loose t-shirt and jacket, the same effect can be seen for the anterior pelvis (Fig. 2i, j, between U1 and U3).

Furthermore, we also observed an effect of changing the orientation of the body parts on the air gap thickness and the contact area. When the ease allowance was sufficient as in the loose t-shirt and jacket, the air gap thickness decreased and the contact area increased at the abdomen due to the change in the orientation of the trunk (Fig. $2 \mathrm{~g}$, h, between U4 and U5). In the posture U4, the garment hanged downwards with a certain 
Fig. 4 The heat transfer coefficients from the study of Mert et al. (2015) for different sizes of homogeneous air layers (case 1), different sizes of folds (case 2) and different frequency of folds (various magnitude of contact area - case 3) for average air gap thickness and their standard deviations (the standard deviations below $0.1 \mathrm{~W} / \mathrm{m}^{2} \mathrm{~K}$ were not shown on the graph)

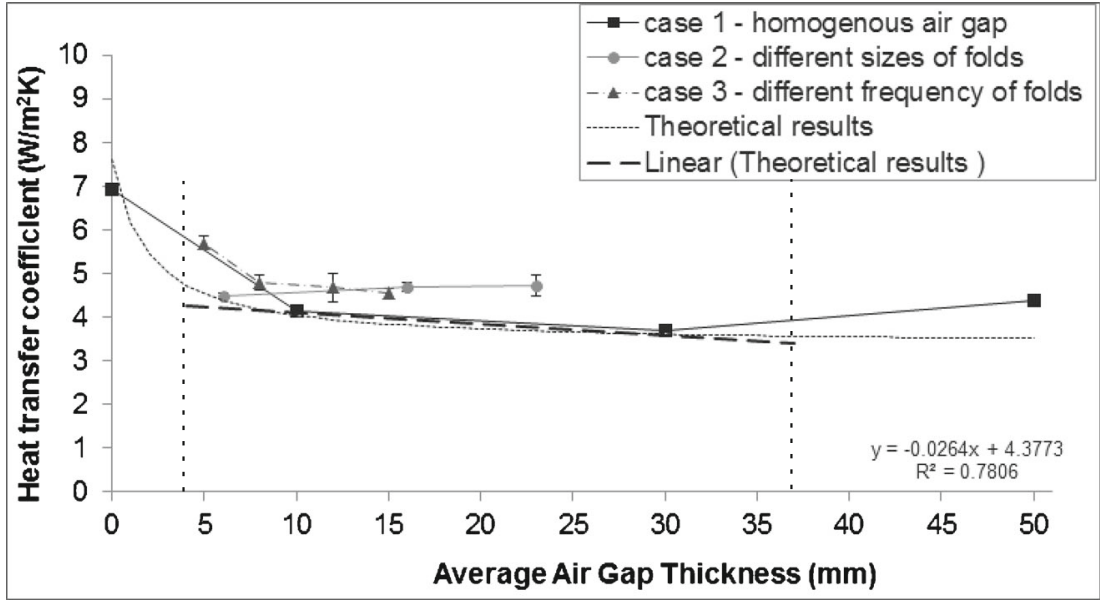

distance from the body below the protruding breasts due to the gravitational force. When the body reclined back (from U4 to U5), the garment fell over the front trunk and conformed to its shape. As a result, the air gap thickness at the abdomen decreased and the contact area increased (as in the case of loose $\mathrm{t}$-shirt and jacket). At the anterior pelvis, the effect of reorientation and bending hip joint occurred at the same time in posture U5, and thus, even though the contact area increased, the air gap thickness showed only a small change due to the orientation change of the trunk (Fig. 2i, j, between U4 and U5).

\section{Effect of body posture for the lower body}

As expected, the selected postures had also an effect on the air gap thickness and the contact area at the lower body due to the compression/buckling and the elongation of the garment. The same effect of bent joint and gravitational force as at the upper body has been observed which effectively increased the air gap thickness for the garment with higher ease allowances (trousers and loose sweatpants) and decreased the contact area for the garment with lower ease allowances (regular sweatpants) at the anterior pelvis by bending the hip (Fig. 3a, b, from L1 to L4 and L1 to L3). In standing posture, the garment conformed to the shape of the pelvis due to the rubber band and belt at the waist of the sweatpants and trousers, respectively. The same increment in the air gap thickness as seen at the anterior pelvis due to bending the hip was expected for the back of the knee and at the adjacent body regions (calf and posterior thigh). However, due to the pressure from the chair in this sitting posture, the air gap thickness decreased and the contact area increased at the posterior thigh for the loose garments (loose sweatpants and trousers) (Fig. 3c, d, from L1 to L2, L1 to L4 and L1 to L3). This fall in the air gap thickness was expected to be higher at the posterior thigh in the posture L3 (sitting straight) than the posture L4 (driving) due to the higher compression at the back of the knee; however, it stayed unaffected. When the manikin was seated on the chair, the pressure between the leg and the chair was exerted and, simultaneously, the garment fell over the anterior thigh due to the gravitational force. Hence, the eased fabric was gathered at both sides of the thigh. As a consequence, the observed change in air gap thickness was similar for both postures L3 and L4 (Fig. 3c, L3 and L4), with the greater change in contact area for the posterior thigh. For the calf, the same effect of this pressure from the bent knee was expected. However, due to the open structure at the ankle of the trousers, the behaviour of the stiff fabric was different than the one on the upper leg and pelvis area which had a closed end at both sides (bent knee and bent hip for upper leg and belt and bent hip for pelvis area).

\section{Effect of garment fit and style}

Even though the garments were confectioned with a substantial increment in ease allowances, the garment fit (regular and loose) and the garment style (t-shirt vs. jacket and sweatpants vs. trousers) had no effect on the air gap thickness at the upper trunk. At the lower trunk and the lower body, the observed trends resulted from both the garment fit and style. The shoulder lengths of each fit and style were designed in the same length. Therefore, the effect of increasing ease allowances at the upper trunk was reduced by the pattern design. Similar findings for the upper body can be seen at the study of Frackiewicz-Kaczmarek et al. (2014b), who investigated the effect of the garment style and fit for the upper body in the standing posture. The sweatpants and the trousers were made with elastic bands and belt to fit the manikin waist, and therefore, the effect of garment fit and style on the air gap thickness at the pelvis area could not be seen only for the standing posture. However, for the other postures (L2, L3 and L4), the effect of garment fit and style is more pronounced with a greater air gap thickness for larger ease allowances. In a nutshell, any change in the air gap at the upper trunk (all postures) and pelvis area (in standing posture) resulted from the body geometry, and not from the garment fit and style, whereas for 
the remaining body regions and postures, the air gap was closely related to the garment fit and style.

\section{Effect of the observed air gap thickness and the contact area on the heat transfer}

The air layers with different orientation (Spencer-Smith 1977) and shapes (Mert et al. 2015) play an important role in the insulation of the garment, and hence, this effect varies in different body postures. In previous studies, Mert et al. (2015) evaluated the effect of different sizes of homogeneous air layers (case 1 and theoretical), different fold sizes (case 2) and different magnitudes of contact area (case 3) on the heat transfer through a combination of a simple fabric and air layer. Figure 4 shows the heat transfer coefficients for these configurations. As it shows, the heat transfer coefficient in combination with homogeneous air gap decreases with the increase of the air gap thickness. The largest increment in the heat transfer coefficient is seen below the $5 \mathrm{~mm}$ of air gap thickness due to prevailing conductive heat exchange and above the $30 \mathrm{~mm}$ due to the development of natural convection. In the present study, majority of the measured air gap cases fell between the 4- and 37-mm range (Figs. 2 and 3), in which the heat transfer coefficient can be potentially linearized due to its flat course. This fact creates an opportunity of calculating the heat transfer coefficient for a homogeneous or close-to-homogenous air layer using the following equation:

$h_{\mathrm{c}}=4.37-0.02 \mathrm{AGT}$

where $h_{\mathrm{c}}\left(\mathrm{W} / \mathrm{m}^{2} \mathrm{~K}\right)$ is the heat transfer coefficient for the calculated homogeneous or close-to-homogeneous air layer and AGT (mm) is the observed average air gap thickness.

The linear model gives heat transfer coefficient the homogeneous or close-to-homogeneous air layers for the air layers between 4 and $37 \mathrm{~mm}$, which is the range of observed case for different body postures for both the upper and lower body. The standard error for this estimation with the linear model is less than $0.15 \mathrm{~W} / \mathrm{m}^{2} \mathrm{~K}$ due to the lower distance between the garment and the body for the air layers below $5 \mathrm{~mm}$ and the possible natural convection for the air layers above $30 \mathrm{~mm}$. Even though the estimated error for calculation of heat coefficient is lower than the $0.15 \mathrm{~W} / \mathrm{m}^{2} \mathrm{~K}$, it should be considered especially for extreme situations (higher heat loss at the air gap lower than $5 \mathrm{~mm}$ due to conductive heat loss and above $30 \mathrm{~mm}$ due to onset of natural convection) (for example, Fig. 2i, jacket for the anterior pelvis in posture U1 and U3; Fig. 3e, for trousers and loose sweatpants in the posture L1 and L4).

\section{Effect of the shape and size of the air layers on heat transfer}

Mert et al. (2015) reported that the heat loss for the folded fabric is greater than for the equivalent homogeneous air gap due to more excessive heat loss at low air gap in the region of the trough than reduction of that heat loss at larger air gap in the region of the peak of the fold. However, this is only valid for folds, of which troughs are in contact with or very close to the heated surface (for example, below $5 \mathrm{~mm}$ in Fig. 4). If the same folded fabric was in a larger distance from the heated surface, the heat transfer coefficients for air gaps at the trough and the peak would not differ much (for example, above $5 \mathrm{~mm}$ in Fig. 4), and consequently, air gaps under such folded fabric could be considered as close-to-homogeneous. For instance, the air layers on the anterior thigh in driving posture (L4) were mostly of irregular shape (see Fig. 1, L4), whilst in standing posture (L1), the air layers were more homogenous (see Fig. 1, L1 for loose garments). Even though the thickness of air layer for both body parts was similar (Fig. 3c), the heat loss through the anterior thigh in driving posture (L4) would be higher than the heat loss through the anterior thigh in standing posture (L1) due to increased contact area creating some thermal bridges at the thigh. The same effect is expected for the other body regions which showed changes in air gap shape with the posture, such as the upper arm (in the posture U1 and U2), calf (in the posture L1 and L2) (Fig. 1).

When the contact area exceeded the threshold of about $42 \%$ as reported by Mert et al. (2015), a steep increase in the heat loss, probably in exponential manner as speculated by Mert et al. (2015), would be observed (Fig. 4, case 3). In the present study, the contact area above $42 \%$ was observed for all upper body garments at the upper back in majority of postures (Fig. 2d). For other body regions, the observed contact area exceeded this threshold for several garment and posture combinations as shown in Figs. 2 and 3. Moreover, according to Spencer-Smith (1977), when the orientation of the air layers of 10, 15 and $20 \mathrm{~mm}$ was changed from vertical to horizontal, the heat loss increased by 17,36 and $33 \%$, respectively. Therefore, in the presented study, the heat loss through the garment at the thigh and lower arm is expected to increase due to the change in the orientation of the limbs (from L1 to $\mathrm{L} 4$ or to $\mathrm{L} 3$ and from $\mathrm{U} 1$ to $\mathrm{U} 2$ ).

The thickness of air layers has been considered in many clothing models (Lotens and Havenith 1991; Li and Holcombe 1998; Fan et al. 2000; Berger and Sari 2000), assuming full contact or homogeneous air layers between the body and the garment. However, the presented study generally showed that the air gap thickness and the contact area are heterogeneous over the body and that the air gap thickness decreased when the body posture changed from standing to sitting. The greatest air gap thickness in standing posture was 32 and $37 \mathrm{~mm}$, whilst in sitting posture 18 and $22 \mathrm{~mm}$ for the 
upper and lower body, respectively. Moreover, the greatest contact area in standing posture was $66-60 \%$, whereas the greatest contact area was $60-52 \%$ for the upper and lower body, respectively. Interestingly, $0 \%$ of contact area was observed on the jacket at the abdomen in posture $\mathrm{U} 2$, and hence, for particular body regions assuming no contact between the body and the garment can be acceptable. Nevertheless, the full contact between the garment and the manikin's body was not observed in this study. The highest contact was found to be $60 \%$ at the posterior pelvis in standing posture with one foot on a footrest due to the increased stress at the buttocks resulting from the asymmetric posture (one leg at the front and the other straight). The greatest contact area for the upper body was $66 \%$. It is possible that the greater contact could occur on the back and buttocks when sitting and leaning on the chair; however, these areas could not be evaluated as they were not visible for the scanner. From the physiological point of view, the changes in air gap thickness and the contact area at the trunk are the most relevant for the body heat loss, since that is the large and warmest body part and even small changes in air gap thickness and contact area may have large overall effect on the body thermal balance. Therefore, it is of great importance to account for the realistic distribution of air layers in the clothing when using clothing models for prediction of the human thermal response and comfort.

\section{General comments}

The findings of this study will help to improve garment design for better protection or to achieve the desired comfort of the body in various work and rest scenarios. The presented study pointed out that regardless of the selected body posture, the heat will be transferred mainly by conduction and radiation at the entire body for the regular fitting garments and at the upper trunk for loose fitting garments due to air gap thickness below the threshold of natural convection. Additionally, when the sweating occurs at the upper trunk, the wicking of the moisture will take place due to the larger contact area and will lead to an increased heat loss due to evaporation. On the other hand, in the loose fitted garments (t-shirt and jacket), the garment had air layers with a thickness larger than the threshold of natural convection which could result in the additional contribution of the convective heat loss. The thickness of air layer decreased below the threshold of natural convection and the magnitude of contact area increased in many postures at both upper and lower body garments. For instance, the contact area was lower than $10 \%$ for all garments at the anterior and posterior thigh in standing posture. When the posture was changed from L1 to L2, L3 or L4, the contact area increased up to around $50 \%$, which is a threshold of increment in heat loss due to the rise in the magnitude of the contact area (Mert et al. 2015) (Fig. 4). In conclusion, with the help of this output from the presented study, the choice of the garment design can be done for the desired body posture including the choice of the garment fit level, fabric mechanical and insulation properties, a need for and fragmentation of body-mapping of a garment, as well as placement and design of vents and closures.

The change in the thickness of air gap and the magnitude of contact area also depends on the relocation of the tissue (fatty tissue and muscles) due to increased pressure between the body parts and the pressure from the object (chair, desk) that touches the skin (Lee and Ashdown 2005; Choi and Ashdown 2011). The fatty tissue would be deformed around the region where the body would have pressure from other body parts, an object or a garment whilst the muscles would change their shape during contraction and relaxation in different postures. In the presented study, it was not possible to scan the nude and clothed human without disturbing the posture and the evaluation of the distortion of the garment in various postures must have been done using a flexible manikin. The manikin could mimic the posture of human body realistically; however, local small-scale deformations, e.g. in muscles and fatty tissue, cannot be evaluated.

\section{Conclusion}

In the present study, the distribution of the air gap thickness and the contact area in regular and loose fitted t-shirts and sweatpants, jacket and trousers and its change in various postures were investigated. It has been proved that the selected body postures had a strong effect on the air gap thickness and the contact area. The influence of the garment fit linked to the pattern and the mechanical properties of the fabric was fundamental, especially for the lower trunk and lower body (except for the pelvis region in standing posture). Moreover, regardless of the selected body posture, the heat will be transferred mainly by conduction and radiation at entire body for the regular fitting garments and at the upper trunk for loose fitting garments due to air gap thickness below the threshold of natural convection. For these cases, a general model for calculating the heat loss was proposed. For the loose garments (loose $\mathrm{t}$-shirt and jacket), an additional contribution of the convective heat loss needs to be estimated on top of the conductive and radiative heat loss estimated by the proposed model.

The outcome of this study suggests that the physical phenomena within clothing can be controlled by the relevant design of the garment for the desired functionality in various postures and could be used to improve the design of the protective and functional sport garments. Moreover, the reported air gap thickness and the contact area in various postures could be used in the mathematical clothing models to more realistically estimate the heat and mass transfer in clothing for various postures. Nevertheless, further studies are required for the investigation of a larger variety of garment types and postures and addressing the tissue deformation on the body. 


\section{References}

Aldrich W (1998) Obtaining repeatability of natural extended upper body positions: its use in comparisons of functional comfort of garments. Journal of fashion marketing\& management 2(4):329-351

ASTM (D 1518:2010) Test method for measuring the evaporative resistance of clothing using a sweating manikin

ASTM (F 2370:2010) Measuring the evaporation resistance of clothing using a sweating manikin

Berger X, Sari H (2000) A new dynamic clothing model. Part 1: heat and mass transfers. Int J Therm Sci 39(6):673-683. doi:10.1016/S12900729(80)00211-6

Choi S, Ashdown SP (2011) 3D body scan analysis of dimensional change in lower body measurements for active body positions. Text Res J 81(1):81-93. doi:10.1177/0040517510377822

Dorman LE, Havenith G (2009) The effects of protective clothing on energy consumption during different activities. Eur J Appl Physiol 105(3):463-470. doi:10.1007/s00421-008-0924-2

Fan JT, Luo ZX, Li Y (2000) Heat and moisture transfer with sorption and condensation in porous clothing assemblies and numerical simulation. Int J Heat Mass Tran 43(16):2989-3000. doi:10.1016/S00179310(99)00235-5

Frackiewicz-Kaczmarek J, Psikuta A, Bueno M, Rossi RM (2014a) Air gap thickness and contact area in undershirts with various moisture contents: influence of garment fit, fabric structure and fiber composition. Text Res J. doi:10.1177/0040517514551458

Frackiewicz-Kaczmarek J, Psikuta A, Bueno M, Rossi RM (2014b) Effect of garment properties on air gap thickness and the contact area distribution. Text Res J. doi:10.1177/0040517514559582

Frackiewicz-Kaczmarek J, Psikuta A, Rossi RM (2012 ) Use of 3D body scanning technique for heat and mass transfer modelling in clothing. International Conference on $3 \mathrm{D}$ body scanning technologies Lugano, Switzerland

Grandjean EE (1980) Sitting posture of car drivers from the point of view of ergonomics. Human Factors in Transport Research 2:205-213

Havenith G, Heus R, Lotens WA (1990a) Clothing ventilation, vapor resistance and permeability index - changes due to posture, movement and wind. Ergonomics 33(8):989-1005. doi:10.1080 /00140139008925308

Havenith G, Heus R, Lotens WA (1990b) Resultant clothing insulationa function of body movement, posture, wind, clothing fit and ensemble thickness. Ergonomics 33(1):67-84. doi:10.1080 /00140139008927094

Havenith G, Nilsson HO (2004) Correction of clothing insulation for movement and wind effects, a meta-analysis. Eur J Appl Physiol 92(6):636-640. doi:10.1007/s00421-004-1113-6

Hes L, de Araujo M (2010) Simulation of the effect of air gaps between the skin and a wet fabric on resulting cooling flow. Text Res J 80(14):1488-1497. doi:10.1177/0040517510361797

ISO (5084:1996) Textiles - determination of thickness of textiles and textile products

ISO (7730:2005) Ergonomics of the thermal environment - analytical determination and interpretation of thermal comfort using calculation of the PMV and PPD indices and local thermal comfort criteria

ISO (8559: 1989) Garment construction and anthropometric surveysbody dimensions

ISO (9073-1:1989) Textiles - test methods for nonwovens - part 1: determination of mass per unit area

ISO (9073-9:2008) Textiles - test methods for nonwovens - part 9: determination of drapability including drape coefficient

ISO (9920:2007) Ergonomics of the thermal environment — estimation of thermal insulation and water vapour resistance of a clothing ensemble

ISO (11226:2000) Ergonomics — evaluation of static working postures
ISO (15831:2004) Clothing - physiological effects - measurement of thermal insulation by means of a thermal manikin

Kirk W, Ibrahim SM (1966) Fundamental relationship of fabric extensibility to anthropometric requirements and garment performance. Text Res J 36(1):37. doi:10.1177/004051756603600105

Lee J, Ashdown SP (2005) Upper body surface change analysis using 3D body scanner. Journal of the Korean Society of Clothing and Textiles 29(12): 1595-1607

Li X, Wang Y, Lu Y (2011) Effects of postures on clothing air gap in protective clothing. Journal of fiber bioengineering \& informatics 4(3):277-283

Li Y, Holcombe BV (1998) Mathematical simulation of heat and moisture transfer in a human-clothing-environment system. Text Res J 68(6): 389-397. doi:10.1177/004051759806800601

Lotens WA, Havenith G (1991) Calculation of clothing insulation and vapor resistance. Ergonomics 34(2):233-254. doi:10.1080 /00140139108967309

Mah T, Song GW (2010) Investigation of the contribution of garment design to thermal protection. Part 1: characterizing air gaps using three-dimensional body scanning for women's protective clothing. Text Res J 80(13):1317-1329. doi:10.1177/0040517509358795

Mayor TS, Couto S, Psikuta A, Rossi RM (2014 ) Transport phenomena in clothing wavy microclimates Paper presented at the Ambeince 14 $\& 10 \mathrm{i} 3 \mathrm{~m}$ Tampere, Finland

Mayor TS, Couto S, Psikuta A, Rossi RM (2015) Advanced modelling of the transport phenomena across horizontal clothing microclimates with natural convection. International Journal of Biometeorology. doi:10.1007/s00484-015-0994-x

McCullough EA, Jones BW, Huck PEJ (1985) A comprehensive data base for estimating clothing insulation. ASHRAE Transactions 91(2A):29-47

Mert E, Psikuta A, Bueno MA, Rossi RM (2015) Effect of heterogenous and homogenous air gaps on dry heat loss through the garment. International Journal of Biometeorology 59(11):1701-1710. doi:10.1007/s00484-015-0978-X

Nielsen R, Olesen BW, Fanger PO (1985) Effect of physical-activity and air velocity on the thermal insulation of clothing. Ergonomics 28(12):1617-1631. doi:10.1080/00140138508963299

Oh AG (2008) The measurement of water vapour transfer rate through clothing system with air gap between layers. Heat and Mass Transfer 44(4):375-379. doi:10.1007/s00231-007-0258-3

Olesen BW, Sliwinska E, Madsen TL, Fanger PO (1982 ) Effect of body posture and activity on the thermal insulation of clothing: measurements by a movable thermal manikin ASHRAE Transactions 88 791-805

Oliveira AVM, Gaspar AR, Quintela DA (2008) Measurements of clothing insulation with a thermal manikin operating under the thermal comfort regulation mode: comparative analysis of the calculation methods. Eur J Appl Physiol 104(4):679-688. doi:10.1007 /s00421-008-0824-5

Parsons K (2003) Human thermal environments - the effects of hot, moderate and cold environments on human health, comfort and performance second edn. Taylor \& Francis Inc., London

Pheasant S (2003) Body space - anthropometry, ergonomics and the design of work, 2nd edn. Taylor \& Francis

Psikuta A, Frackiewicz-Kaczmarek J, Frydrych I, Rossi R (2012) Quantitative evaluation of air gap thickness and contact area between body and garment. Text Res J 82(14):1405-1413. doi:10.1177/0040517512436823

Psikuta A, Frackiewicz-Kaczmarek J, Mert E, Bueno M, Rossi RM (2015 ) Validation of a novel 3D scanning method for determination of the air gap in clothing Measurement doi:10.1016/ j.measurement.2015.02.024

Spencer-Smith JL (1977) The physical basis of clothing comfort. Part 2 heat transfer through dry clothing assemblies. Clothing Research Journal 5(1):3-17 
Takada S, Hokoi S, Kawakami N, Kudo M (1999) Effect of sweat accumulation in clothing on transient thermophysiological response of human body to environment. Building simulation proceedings 1 : $385-392$

Umeno T, Hokoi S, Takada S (2001 ) Prediction of skin and clothing temperatures under transient considering moisture accumulation in clothing. ASHRAE Trans 10771 - 81

Wang X, Bullock MI (2004 ) Pedal operation, preferred postures for driving In: Delleman NJ, Heslegrave CM, Chaffin DB (eds)
Working postures and movements-tools for evaluation and engineering CRC Press

Winslow CEA, Gagge AP, Herrington LP (1939) The influence of air movement upon heat losses from the clothed human body. Am J Physiol 127(3):505-518

Wu YS, Fan JT, Yu W (2011) Effect of posture positions on the evaporative resistance and thermal insulation of clothing. Ergonomics 54(3):301-313. doi:10.1080 /00140139.2010.547604 